\title{
Epidemiology of medication-related problems in children with kidney disease
}

\author{
Norkasihan Ibrahim • Ian Chi Kei Wong • \\ Stephen Tomlin • Manish D. Sinha • Lesley Rees • \\ Yogini Jani
}

Received: 6 July 2014 /Revised: 4 September 2014 / Accepted: 5 September 2014 / Published online: 29 October 2014

(C) The Author(s) 2014. This article is published with open access at Springerlink.com

\begin{abstract}
Background Medication-related problems (MRPs) are the undesirable effects of pharmacotherapy that can potentially lead to harm. The epidemiology of MRPs in paediatric renal patients is unknown. We aimed to characterise MRPs in this population at two tertiary care hospitals in the UK.

Methods Prescription charts for children ( $\leq 18$ years) were reviewed to identify MRPs, and characterised using a specific proforma with a standard operational definition. MRP predictors were evaluated by logistic regression and severity was assessed using a validated scale.

Results Two hundred and sixty-seven MRPs were identified from 266 prescription chart reviews. The incidence was $51.2 \%$ (203 MRPs, 166 charts; $95 \%$ CI 43.2-60.6\%) of hospitalised patients and $32 \%$ (64 MRPs, 100 charts; $95 \%$ CI $22.9-41.1 \%$ ) in outpatients. The number of prescribed medications was the only independent predictor during inpatient
\end{abstract}

N. Ibrahim • I. C. K. Wong $\cdot$ Y. Jani

Centre for Paediatric Pharmacy Research, School of Pharmacy,

University College London, London, UK

N. Ibrahim

Pharmacy Department, Paediatric Institute, General Hospital Kuala

Lumpur, 50586 Jalan Pahang, Kuala Lumpur, Malaysia

I. C. K. Wong

Centre for Safe Medication Practice and Research, Department of Pharmacology and Pharmacy, Li Ka Shing Faculty of Medicine,

University of Hong Kong, Hong Kong, China

S. Tomlin

Pharmacy Department, Evelina London Children's Hospital, Guy's and St. Thomas' Hospital NHS Foundation Trust, King's Health

Partners, London, UK

M. D. Sinha

Department of Paediatric Nephrology, Evelina London Children's Hospital, Guy's and St. Thomas' Hospital NHS Foundation Trust,

King's Health Partners, London, UK treatment (OR 1.06, $95 \%$ CI 1.02-1.10, $p=0.002)$ with no significant predictors identified at outpatient clinics. The severity level of the MRPs was minor: $53.9 \%$, (144 out of 267); or moderate: $46.1 \%$, (123 out of 267). Sub-optimal drug effect was the predominant MRP (inpatient: $68 \%$; outpatient: $39 \%$ ). Prescribing error and patients' medicine-taking behaviour were the main contributory factors. The majority of the MRPs in the inpatient setting were resolved.

Conclusion Many factors are associated with MRPs in children; the associations are cumulative and interdependent. Investment in preventive strategies and extending the support from the acute health care setting into the community are invaluable for optimising pharmacotherapy.

Keywords Paediatric nephrology $\cdot$ Medication safety · Prescribing errors $\cdot$ Pharmacotherapy $\cdot$ Drug-related problems

L. Rees

Department of Nephrology, Great Ormond Street Hospital NHS

Foundation Trust, London, UK

Y. Jani

Pharmacy Department, University College London Hospital NHS

Foundation Trust, London, UK

I. C. K. Wong $(\square)$

Li Ka Shing Faculty of Medicine, University of Hong Kong, 2/F, 21

Sassoon Road, Laboratory Block, Faculty of Medicine Building,

Hong Kong, China

e-mail: wongick@hku.hk 


\section{Introduction}

Medications are prescribed with the intention of benefiting the patient. However, the use of medications can be undesirable and potentially lead to harm. These undesirable effects are known as medication-related problems (MRPs). A MRP is defined as an event involving pharmacotherapy that interferes with the patient experiencing an optimal outcome of medical care [1]. Medications for patients with kidney disease are specialised and complex. In those with chronic kidney disease (CKD), the relevance of optimal pharmacotherapy management is even more critical, thus putting this group of children at risk of developing MRPs. The National Kidney Foundation/Kidney Dialysis Outcome Quality Indicator $(\mathrm{NKF} / \mathrm{KDOQI})$ guideline recommends that a medication review should be performed for children and adolescents at all visits for the prevention of MRPs such as inappropriate doses, inadequate therapeutic monitoring and potentially adverse drug effects on the kidney or disease complications [2].

Medication-related problems are common in children: recent studies have reported that the incidence in the UK is $39.4 \%$ in hospitalised children [3] and $2.7 \%$ of children on medications were admitted to the emergency departments in the UK [4]. However, these studies did not include paediatric renal patients. Current management of MRPs in this group is based on what has been learned from adult studies [5], which may be unrepresentative of the paediatric population. We have previously reported on the paucity of data on the epidemiology of MRPs in children with kidney disease and suggested further studies for proactive strategies in medication safety [5]. This current study aimed to determine the characteristics of MRPs and potential risk factors for their occurrence in children with kidney disease at the tertiary renal centres.

\section{Materials and methods}

\section{Setting and study subjects}

Two observational cohort studies were conducted at the renal unit of the Evelina London Children's Hospital (ELCH) and Great Ormond Street Hospital for Children (GOSH). Study 1 was conducted in an inpatient setting at ELCH and GOSH and study 2 was conducted in the renal outpatient clinics at ELCH. Approval was obtained from the Research Ethics Committee, UK. Both hospitals are two of the largest children's renal centres and provide tertiary care to approximately $40 \%$ of children requiring renal replacement therapy (RRT) in the UK [6]. The renal units are led by teams of paediatric nephrologists, supported by a team of healthcare professionals including specialist renal nurses, renal pharmacists and nutritionists. The cases seen in both units include all aspects of paediatric renal disease, including RRT.
Study 1, inpatient setting The clinical team in both hospitals conducted daily a full patient review and clinical rounds. Clinical pharmacy practice is established as standard care in the inpatient setting; this enabled the pharmacists to review prescription charts as a standard clinical routine. Prescription chart review was conducted using paper documentation in ELCH and from an electronic prescribing system (ePS) in GOSH.

Study 2, outpatient clinic setting The renal outpatient clinics in ELCH operate daily on weekdays. Patients' clinic notes and medication lists were documented on a multidisciplinary electronic medical record (eMR). Unlike the inpatient setting, clinical pharmacy practice is not part of the standard care and thus, prescription chart review was not routine for all patients attending the clinic.

The inclusion criteria for both studies were the same: all children aged 18 years and younger, who had received at least one long-term (non-acute) medication. Additionally, children who were included in the inpatient study had to have been hospitalised for at least $24 \mathrm{~h}$.

\section{Data collection}

Study 1, inpatient study Data were collected for hospitalised patients at ELCH and GOSH from 1 December 2011 to 1 September 2012. At each site, one pharmacist was responsible for the detection of MRPs using a structured tool and prospective prescription chart review method during routine clinical practice. Recommendations on the resolution of the MRPs were discussed with the clinical team during clinical rounds; this method has been used in previous paediatric MRP studies [3, 4, 7, 8].

Study 2, outpatient clinic study Data were collected at ELCH from 18 February to 18 September 2013. As clinical pharmacy practice was not a standard care at the outpatient clinic and in order to ensure the consistency of data, one researcher was responsible for identifying MRPs from the eMR, using a structured approach. In the event that an MRP with potential harm to the patient was identified, the researcher would alert the clinical team.

The two pharmacists who were involved in collecting the data in the inpatient setting had received similar professional training and each had more than 10 years' experience in tertiary paediatric renal pharmacy practice. The researcher is also a qualified pharmacist trained in renal pharmacy, but not working in the capacity of a pharmacist within the Trusts. The pharmacists and the researcher received training on the definition and characteristics of MRPs before initiation of the research. All MRPs were recorded onto a proforma using a standard code and operational definition (Appendix 1). All prescribed medications associated with MRPs were classified according to the World Health Organisation Anatomical Therapeutic Chemical (WHO-ATC) system. 
All different medications prescribed throughout the patients' hospital stay (in study 1) and all medications listed in the patient's clinic notes (in study 2 ) were recorded.

Incidence and risk factors

The incidence of MRPs in the study cohort was defined as the number of patients with at least one MRP identified during prescription chart review, divided by the total number of patients reviewed multiplied by 100 . For MRP incidence and risk factor calculations, only the first event of MRP identified during review was considered for investigating the association between MRP incidence and potential risk factors.

\section{Analysis of MRP severity}

Similar to previously published paediatric MRP studies $[3,9]$ this project adopted a validated severity scoring tool for medication errors [10]. The MRPs were independently assessed by four health care professionals comprising a paediatric nephrology consultant, paediatric consultant pharmacist, medication safety pharmacist and a specialist renal nurse. The MRPs were assessed in terms of clinical significance, with scores ranging from 0 to 10 using a visual analogue scale, where 0 represented a case with no potential harm and 10 represented a case that would result in death. An MRP was considered minor (unlikely to have any adverse effects) if the score was $<3$, moderate (likely to cause some adverse effects or interfere with therapeutic goals) if the score was between 3 and 7, or severe (likely to cause lasting impairment or death) if the score was $>7$. The mean severity score ( $\mu$ Score) from all assessors was the final score assigned to each MRP.

\section{Classification of medications and MRPs}

The medications that were associated with MRPs were classified according to the WHO-ATC system. The identified MRPs were documented in a specified proforma adapted from the Pharmaceutical Care Network Europe (PCNE) MRP Classification Scheme [11]. The operational definition of the types and contributory factors of MRPs is available in Appendix 1.

\section{MRP resolution}

Prescription review was not standard clinical practice in the outpatient clinic; thus, corrective measures and resolution rates could only feasibly be evaluated for MRPs identified during study 1 , in the inpatient setting. A MRP was defined as "solved" on occasions when actions were taken before causing any harm to patients or actions were taken to solve an ongoing MRP.

\section{Statistics}

Data were analysed using the Statistical Package for Social Science (SPSS) version 21 and presented as percentages (\%), mean with standard deviation (SD) or median with interquartile range (IQR 1-3) and odds ratios (OR) with $95 \%$ confidence interval (CI). For the descriptive analysis of patient and MRP characteristics, Chi-squared $\left(\chi^{2}\right)$, Kruskal-Wallis, Rank and Mann-Whitney tests were used as appropriate. In all statistical tests $p$ values of less than 0.05 were considered statistically significant.

Multivariate logistic regression was performed to assess the impact of predictors on the likelihood MRPs would occur among the study population. The regression worked around one binary outcome (at least one MRP identified: yes/no) and six independent variables: age (years), gender, number of medications prescribed (Rx) and types of RRT (dialysis, posttransplant and non-RRT). The variable Rx refers to the number of different medications that were prescribed during the data collection period. Additional independent variables analysed in the inpatient study were length of hospital stay in days (LOS) and types of ward admission (elective or non-elective). Elective admission refers to scheduled admission to the ward for inpatient treatment or procedure. Non-elective admission refers to cases transferred from other wards or hospitals for continuation of care. The factors that were analysed in the regression analyses included those found to be relevant in the literature and of pathophysiological significance [3, 12-14].

\section{Results}

A total of 227 patients fulfilled the inclusion criteria and 267 MRPs were identified (Inpatient, $\mathrm{n}=127$ patients, 203 MRPs (mean 1.2 MRPs per patient (SD 2); Outpatient, $\mathrm{n}=100$ patients, 64 MRPs (mean 0.6 MRPs per patient (SD 1.4)). All MRPs were included for analyses. The incidence of MRPs in the inpatient cohort was $19.2 \%$ higher than the Outpatient cohort $(51.2 \%, 95 \%$ CI $43.2-60.6 \%$ vs. $32 \%, 95 \%$ CI $22.9-$ $41.1 \%, \mathrm{p}=0.04)$. The study results are summarised in Table 1 .

\section{Characteristics of the study population}

The majority of patients were male. Inpatients were younger than the outpatient cohort (inpatient: median 6.6 years [IQR 1.8 12.5]; outpatient: median 9.7 (IQR 5.7-14.2), $p=<0.001$ ). Inpatients who developed MRPs, compared with those who did not, had a longer length of hospital stay (median 9 vs 4 days, $p<0.001)$, were on dialysis or had kidney transplant $(p=0.001)$ 
Table 1 Summary of results for study 1 (inpatient setting) and study 2 (outpatient renal clinic)

\begin{tabular}{lll}
\hline & Study 1: inpatient setting & Study 2: outpatient renal clinic \\
\hline Number of patients recruited & 127 & 100 \\
Gender (male) & $53.5 \%, n=68$ & $55 \%, n=55$ \\
Median age (IQR) of children with MRPs & $5.0(1.3-11.9)$ & $10.3(5.2-13.8)$ \\
MRP incidence per patient reviewed $(95 \%$ CI) & $51.2 \%(43.2-60.6)$ & $32 \%(22.9-41.1)$ \\
Significant risk factor for the occurrence of MRPs & The numbers of medicine prescribed per child & None identified \\
Total MRPs identified $(n=227)$ & 203 MRPs & 64 MRPs \\
MRP severity level & Minor $68 \%, 138$ out of 203 & Minor $9.4 \%, 6$ out of 64 \\
& Moderate $32 \%, 65$ out of 203 & Moderate $90.6 \%, 58$ out of 64 \\
Predominant MRPs & Sub-optimal drug effect $21.7 \%, 44$ out of 203 & Sub-optimal drug effect $39.1 \%, 25$ out of 64 \\
MRP resolution rate & Solved DRPs $96 \%, 195$ out of 203 & Not evaluated \\
\hline
\end{tabular}

$M R P$ medication-related problem, $D R P$ drug-related problem

and more medications prescribed $(p<0.001$; Table 2). Of the 127 inpatients, 6 were diagnosed with acute kidney injury (AKI). Of the 6 AKI cases, 1 was secondary to sepsis and another was due to the use of radio-contrast agent. The remaining 4 cases could not be confirmed to have any association with the use of medications as they had unknown causes.

\section{Risk factors for MRPs}

The number of medications prescribed per child was the single significant predictor for MRPs at the inpatient setting (OR $1.06,95 \%$ CI 1.02-1.10, $p=0.002$ ). The odds ratio of 1.06 indicates that the chance of having an MRP is $6 \%$ higher with every additional medication. There was a trend toward a higher prediction of MRPs in patients on dialysis compared with those not on dialysis, but this finding was not statistically significant. None of the predictors analysed here was statistically significant for the outpatient cohort.

\section{MRP severity assessment}

The 64 MRPs identified from the outpatient clinic scored higher on the severity scale compared with the 203 MRPs identified in the inpatient setting ( $\mu$ Score range: outpatient clinic: 2.1-5.8; inpatient 0.1-6.8).

\section{Medications associated with MRPs}

The groups of medicines most often associated with MRPs were those used for "alimentary tract and metabolism", "systemic anti-infective" and "blood and blood forming organs" (Table 3). MRPs in inpatients were commonly reported with the use of nystatin $7.9 \%, 16$ out of 203$)$, paracetamol ( $7.4 \%$,

Table 2 Patient demographic characteristics

\begin{tabular}{|c|c|c|c|c|c|c|}
\hline & \multicolumn{3}{|c|}{ Inpatients $(N=127)$} & \multicolumn{3}{|c|}{ Outpatient clinic $(N=100)$} \\
\hline & $\mathrm{MRPs}^{\mathrm{b}}$ & No MRPs & $p$ value & $\mathrm{MRPs}^{\mathrm{b}}$ & No MRPs & $p$ value \\
\hline Gender & & & 0.44 & & & 0.76 \\
\hline Male & $37(29.1)$ & $31(24.4)$ & & $17(17.0)$ & $38(45.0)$ & \\
\hline Female & $28(22.0)$ & $31(24.4)$ & & $15(15.0)$ & $30(37.0)$ & \\
\hline Median age & $5.0(1.3-11.9)$ & $8.1(2.1-13.2)$ & 0.22 & $10.3(5.2-13.8)$ & $9.3(5.7-14.4)$ & 0.85 \\
\hline Median length of hospital stay (days) & $9(4-20)$ & $4(3-7)$ & $<0.001$ & NA & NA & NA \\
\hline Type of ward admission & & & 0.45 & NA & NA & NA \\
\hline Elective & $41(32.3)$ & $35(27.6)$ & & & & \\
\hline Non-elective & $24(18.9)$ & $27(21.3)$ & & & & \\
\hline Renal replacement therapy & & & 0.001 & & & 0.38 \\
\hline Dialysis & $20(15.7)$ & $8(6.3)$ & & $13(13.0)$ & $22(22.0)$ & \\
\hline Kidney transplant & $18(14.2)$ & $11(8.7)$ & & $7(7.0)$ & $12(12.0)$ & \\
\hline No RRT & $27(21.3)$ & $43(33.9)$ & & $12(12.0)$ & $34(34.0)$ & \\
\hline Median number of medicines prescribed per child $\mathrm{d}^{\mathrm{a}}$ & $28(13-15)$ & $10(7-19)$ & $<0.001$ & $5(3-7)$ & $5(3-7)$ & 0.55 \\
\hline
\end{tabular}

Data are median (IQR 1-3) or frequency (\% of $N$ ) RRT renal replacement therapy, MRP medication-related problem

${ }^{a}$ Median number of medicines prescribed throughout hospital stay

${ }^{\mathrm{b}}$ At least one MRP identified during prescription review 
15 out of 203) and ranitidine $(5.4 \%, 11$ out of 203$)$, whereas MRPs in outpatients were associated with prednisolone (15.6\%, 10 out of 64$)$, sodium bicarbonate $(9.4 \%, 6$ out of $64)$ and alfacalcidol $(7.8 \%, 5$ out of 64$)$.

The types and contributory factors of MRPs

Sub-optimal drug effect was the predominant MRP identified in both clinical settings; however, their contributory factors were distinct. The characteristics of the MRPs are presented in Table 4.

\section{Inpatient setting}

The predominant MRPs were "sub-optimal drug effect" $(21.7 \%, 44$ out of 203$)$, "unnecessary treatment" (20.2\%, 41 out of 203) and "toxic adverse reaction" (19.2\%, 39 out of 203). The majority of the MRPs were identified and resolved before they caused any harm $(55.1 \%, 112$ out of 203). Prescribing errors in the selection of medications and doses were the main contributory factors for the occurrence of MRPs. The following are examples of cases:

MRP1 Valganciclovir $400 \mathrm{mg}$ once a day was prescribed post-transplant; the dose should have been optimised to $500 \mathrm{mg}$ according to renal function ( $\mu$ Score 2.8).

MRP2 $50 \mathrm{mcg}$ stat dose of intravenous prazosin was prescribed to a neonate, but $500 \mathrm{mcg}$ was administered ( $\mu$ Score 5.5).

MRP3 Intravenous gentamicin for septicaemia was prescribed for a patient with acute renal dysfunction; daily doses of gentamicin were continued for 2 weeks without the serum drug level being monitored ( $\mu$ Score 7.4).

\section{Outpatient clinic}

The predominant MRPs were "sub-optimal drug effect" $(39.1 \%, 25$ out of 64$)$, "drug administration problems"

Table 3 Medications associated with MRPs

\begin{tabular}{|c|c|c|}
\hline WHO ATC code & $\begin{array}{l}\text { Study 1: inpatient } \\
n \text { (\% of 203) }\end{array}$ & $\begin{array}{l}\text { Study 2: outpatient clinics } \\
n(\% \text { of } 64)\end{array}$ \\
\hline \multicolumn{3}{|l|}{ (A) Alimentary tract and metabolism ${ }^{\mathrm{a}}$} \\
\hline Nystatin, ranitidine, alfacalcidol, calcium carbonate ${ }^{\mathrm{b}}$ & $52(25.6)$ & $12(18.8)$ \\
\hline \multicolumn{3}{|l|}{ (B) Blood and blood-forming organs ${ }^{\mathrm{a}}$} \\
\hline Acetylsalicylic acid, erythropoietin, electrolytes (e.g., sodium bicarbonate/chloride) ${ }^{\mathrm{b}}$ & $27(13.3)$ & $15(23.4)$ \\
\hline \multicolumn{3}{|l|}{ (C) Cardiovascular system } \\
\hline Enalapril, furosemide, nifedipine ${ }^{b}$ & $10(4.9)$ & $2(3.1)$ \\
\hline \multicolumn{3}{|l|}{ (D) Dermatological } \\
\hline Fusidic acid, gentamicin, mupirocin ${ }^{\mathrm{b}}$ & $4(2)$ & 0 \\
\hline \multicolumn{3}{|l|}{ (G) Genitourinary system and sex hormones } \\
\hline Oxybutinin $^{\mathrm{b}}$ & $2(1)$ & 0 \\
\hline \multicolumn{3}{|l|}{ (H) Systemic hormonal preparations, excluding sex hormones } \\
\hline Steroids-based products (e.g., prednisolone, methylprednisolone), octreotide, levothyroxine ${ }^{\mathrm{b}}$ & $15(7.4)$ & $10(15.6)$ \\
\hline \multicolumn{3}{|l|}{ (J) Anti-infectives for systemic use $\mathrm{e}^{\mathrm{a}}$} \\
\hline Penicillins, cephalosporins, vaccines ${ }^{\mathrm{b}}$ & $49(24.1)$ & $11(17.2)$ \\
\hline \multicolumn{3}{|l|}{ (L) Antineoplastic and immunomodulating agents } \\
\hline Tacrolimus, mycophenolic acid, ciclosporine, cyclophosphamide ${ }^{\mathrm{b}}$ & $11(5.4)$ & $10(15.6)$ \\
\hline \multicolumn{3}{|l|}{ (M) Musculo-skeletal system } \\
\hline Pamidronic acid ${ }^{\mathrm{b}}$ & $1(0.5)$ & 0 \\
\hline \multicolumn{3}{|l|}{ (N) Nervous system } \\
\hline Paracetamol, morphine, codeine & $23(11.3)$ & $3(4.7)$ \\
\hline \multicolumn{3}{|l|}{ (P) Antiparasitic products, insecticides and repellents } \\
\hline Levimasole $^{\mathrm{b}}$ & $1(0.5)$ & $1(1.6)$ \\
\hline \multicolumn{3}{|l|}{ (R) Respiratory system } \\
\hline Cyclizine, fluticasone, cetrizine ${ }^{b}$ & $7(3.4)$ & 0 \\
\hline \multicolumn{3}{|l|}{ (S) Sensory organs } \\
\hline Dexamethasone and anti-infectives ${ }^{\mathrm{b}}$ & $1(0.5)$ & 0 \\
\hline \multicolumn{3}{|l|}{ (V) Various } \\
\hline Polystyrene sulfonate ${ }^{\mathrm{b}}$ & $1(0.5)$ & 0 \\
\hline
\end{tabular}

WHO ATC World Health Organisation Anatomical Therapeutic Chemical system

${ }^{\text {a }}$ The predominant groups

${ }^{\mathrm{b}}$ The most common medicines reported in each group 
Table 4 Types of medication-related problems (MRPs) identified in the study cohort by the main and sub-categories ${ }^{\mathrm{a}}$

\begin{tabular}{|c|c|c|c|c|c|}
\hline \multirow[t]{2}{*}{ MRP characteristics } & & \multicolumn{2}{|c|}{ Study 1 , inpatient setting } & \multicolumn{2}{|c|}{ Study 2, outpatient clinic } \\
\hline & & $n(\%)$ & & $n(\%)$ & \\
\hline \multirow[t]{10}{*}{ Types of MRPs } & P1.1 No effect of drug treatment & $3 / 203$ & $(1.5)$ & $0 / 64$ & \\
\hline & P1.2 Sub-optimal effect & $44 / 203$ & $(21.7)$ & $25 / 64$ & $(39.1)$ \\
\hline & P1.4 Untreated indication & $20 / 203$ & $(9.9)$ & $1 / 64$ & $(1.6)$ \\
\hline & P2.1 Non-allergic reaction & $22 / 203$ & $(10.8)$ & $11 / 64$ & $(17.2)$ \\
\hline & P2.2 Allergic drug reaction & $3 / 203$ & $(1.5)$ & $1 / 64$ & $(1.6)$ \\
\hline & P2.3 Toxic adverse reaction & $39 / 203$ & $(19.2)$ & $2 / 64$ & $(3.1)$ \\
\hline & P3.1 Unnecessary treatment & $41 / 203$ & $(20.2)$ & $0 / 64$ & \\
\hline & P4.1 Patient dissatisfaction & $1 / 203$ & $(0.5)$ & $0 / 64$ & \\
\hline & P4.2 Drug administration problems & $30 / 203$ & $(14.8)$ & $19 / 64$ & $(29.7)$ \\
\hline & P4.3 Delay in treatment & $0 / 203$ & & $5 / 64$ & $(7.8)$ \\
\hline \multirow[t]{8}{*}{ Contributory factors for MRPs ${ }^{\mathrm{b}}$} & C1 Inappropriate drug selection & $72 / 399$ & $(18.0)$ & $3 / 73$ & $(4.1)$ \\
\hline & C2 Inappropriate drug form & $7 / 399$ & $(1.8)$ & $0 / 73$ & \\
\hline & C3 Inappropriate drug dosage & $97 / 399$ & $(24.3)$ & $4 / 73$ & $(5.5)$ \\
\hline & $\mathrm{C} 4$ Inappropriate treatment duration & $15 / 399$ & $(3.8)$ & $0 / 73$ & \\
\hline & C5 Medication errors & $181 / 399$ & $(45.4)$ & $1 / 73$ & $(1.4)$ \\
\hline & C6 Drug supply problems & $0 / 399$ & & $8 / 73$ & $(11.0)$ \\
\hline & C7 Patient factors & $1 / 399$ & $(0.3)$ & $31 / 73$ & $(42.5)$ \\
\hline & C8 Other factors & $26 / 399$ & $(6.5)$ & $26 / 73$ & $(35.6)$ \\
\hline
\end{tabular}

${ }^{a}$ The operational definition for the types and contributory factors of MRPs is available in Appendix 1

${ }^{\mathrm{b}}$ Full description of the contributory factors for MRPs is available in Appendix 2.

$(29.7 \%, 19$ out of 64$)$ and "non-allergic adverse drug events" (17.2\%, 11 out of 64$)$. The contributory factors for MRPs were associated with patients' medicine-taking behaviour and other factors (e.g. unwanted side effects and dependency on feeding tubes for the administration of medications). The following are examples of cases:

MRP1 A patient with vesicoureteric reflux was dependent on the enteral feeding tube. The family struggled to administer iron supplement (and other oral medications) as prescribed ( $\mu$ Score 2.1).

MRP2 Activated vitamin D for the prevention of hyperparathyroidism was prescribed to a patient with advanced kidney failure. The family had problems in obtaining a continuous supply in the community setting ( $\mu$ Score 3.9).

MRP3 A patient had on-going proteinuria, but had been non-compliant with treatment for the past 6 months ( $\mu$ Score 5.8).

\section{MRP resolution}

Of the 203 MRPs identified from the inpatient setting, $96 \%$ (195 out of 203) were resolved as a result of multidisciplinary care. Most MRPs were resolved by changes to the medication selection, doses and dosing frequency. The pharmacists played an important role in providing consultations on medication regimens and $99.5 \%$ of the recommendations (227 out of 228) were accepted by the clinical team.

\section{Discussion}

To our knowledge this is the first study investigating MRPs systematically in children with kidney disease in the UK. We observed that whilst not all predictors for MRPs were significant, our results are particularly important, not only in understanding the characteristics of MRPs in this population, but also in enabling the development of preventive strategies in clinical practice.

It is worth discussing further the differences in the demographic characteristics between study subjects in the inpatient and outpatient setting in the current research. Even though all subjects were children with kidney disease, the majority of those seen at the outpatient clinics were in the pre-dialysis stage. Our study shows that those receiving inpatient treatments require three times the numbers of medications than the outpatient cohort (median 17 vs 5 medications per child). Children receiving inpatient treatment were by definition more ill and this was likely due to more advanced disease or complications of RRT. Many studies in adults with CKD have previously demonstrated that patients at the late stage of CKD and on RRT require more complex pharmacotherapy and are exposed to increased chances of MRPs [15, 16]. There was an association between the 
occurrence of MRP and the length of hospital stay; however, further research is required to assess causality.

Interestingly, despite having more serious clinical conditions in hospitalised patients, the majority of MRPs were scored as minor $(68 \%, 138$ out of 203$)$ compared with the MRPs identified at the outpatient clinic in which $90.6 \%$ (58 out of 64) were scored as moderate. The possible reason for this lies in the difference of care between tertiary care centres and the community. Problems in the use of medications occurring in inpatients are "active errors" [17]. Similar to previous paediatric medication error research $[7,8,18,19]$ the majority of the "active errors" in the current study were caused by prescribing errors. These errors could rapidly be rectified by the healthcare professionals and were less likely to cause harm as a result of the interventions. As an example, suboptimal tacrolimus dose in the management of post-kidney transplantation on the ward could be adjusted from post-12-h tacrolimus serum drug levels. Changes to drug regimens are directly monitored and patients receiving inpatient treatment are likely to adhere to the prescribed therapy.

In contrast, drug problems occurring in the community are "latent errors", most of which are caused by exogenous factors that are beyond the control of healthcare professionals [20]. An example of exogenous factors in the current research was difficulties in obtaining unlicensed and off-label medications from the community.

The types of medications associated with MRPs in our study portrayed the common prescribing pattern in the paediatric population [3, 21, 22]. However, medicines of the "blood and blood forming agents" are unique to MRPs in renal patients $[12,13,23,24]$. The medications that were more often associated with MRPs were also those more often prescribed. It is also important to note that there are limited data available for the safe and effective doses of most medications used in children $[3,25]$. This may contributed to the observed tendency for higher numbers of adverse drug events and other MRPs in this cohort.

It is a challenging task to determine an optimal and safe dose for children with kidney disease owing to their physiology and the altered pharmacokinetic properties of medications $[21,26]$. The management of MRPs should be a shared responsibility of all healthcare providers. The MRP classifications and the MRP screening tool used in the present research could also be integrated into the physician's practice.

Other strategies to reduce the occurrence of MRPs are to integrate medication reconciliation into patients' medicine management program. This program was also recently highlighted for the care of adult renal patients [27, 28]. In the UK, a survey among paediatric pharmacists found that only $34 \%$ had full medication reconciliation in place [29]. A policy on medication reconciliation on hospital admission and at discharge, including routine outpatient clinic appointments, minimises discrepancies in the transfer of information [3].
In the inpatient setting, we found that most MRPs are largely attributed to prescribing errors. Prescribing errors have been reported to be preventable; thus, having continuous awareness programmes on medication safety in paediatrics remains essential in practice [8, 29-32].

This study reported the rate of MRP occurrence in children who attended the renal outpatient clinic as less than one MRP per patient. Nevertheless, the potential harm as a consequence of these MRPs should not be underestimated. The latent effect of MRPs in this patient group has not been studied. We identified cases of poor treatment outcome due to patient non-adherence. An example of these cases that was highlighted earlier involved a patient with glomerulonephritis leading to persistent proteinuria.

Difficulties in obtaining medication supplies and poor understanding about medications among parents and children are among the factors causing low adherence in CKD [15, 33]. Thus, proper coordination of supplies of medication in the community is also vitally important and should be anticipated when unlicensed and/or off-label medications are prescribed for children. Continuous assessment on changing patients' cognitive behaviour towards medicines and/or specific clinical outcomes is also important to empower patients' involvement in managing their medications $[15,32,34]$. As caring for children with kidney disease is a life-long commitment, parents/carers would benefit from a support system to facilitate them in the monitoring, prevention and resolution of MRPs.

The strengths of this research lie in using multiple approaches to identifying MRPs, i.e. a prospective chart review in the inpatient setting and a retrospective chart review in the outpatient clinic. We were aware that the characteristics of MRPs identified in both studies reflect the types of methods used. Thus, appropriate measures had been taken to minimise the variability of data that include the use of a structured proforma with a standard operational definition and training to those involved in collecting the data. This research included two main referral centres for paediatric nephrology in London. Thus, the results may not necessarily be generalisable to other countries with different care settings.

\section{Conclusion}

Medication-related problems in children with kidney disease necessitate a comprehensive approach to their identification and resolution. The MRPs in different clinical settings are unique in their characteristics and levels of severity. Investment in preventive strategies and extending the support from the health care setting into the community are invaluable for optimising pharmacotherapy.

Acknowledgement The authors wish to thank the Ministry of Health Malaysia for funding Norkasihan Ibrahim in this PhD research, Deborah 
Riddout and Monalis Bagkeris of UCL Institute of Child Health for their statistical advice, the Renal and Pharmacy team of ELCH and GOSH, especially William Thornhill, Susan Patey, Christine Booth, Nikesh Gudka and Iek Leng Cheng for their professional cooperation.
Ethics approval This study was performed in accordance with the ethical standards laid down in the 1964 Declaration of Helsinki; approved by the National Research Ethics Committee, London, UK (11/LO/0879; $12 / \mathrm{LO} / 0709$ ) and informed consent was given to all subjects before inclusion.

\section{Appendix 1}

Table 5 Coding system for the types and contributory factors of medication-related problems (MRPs) and the operational definition of the modified Pharmaceutical Care Network (PCNE) MRP classification version 6.2

\begin{tabular}{|c|c|c|c|}
\hline $\begin{array}{l}\text { Main category: } \\
\text { types of MRPs }\end{array}$ & Codes & Sub-categories & Operational definition \\
\hline \multirow[t]{5}{*}{ Drug effect } & $\mathrm{P} 1$ & & There is a (potential or manifested) problem with the (lack of) effect of the pharmacotherapy \\
\hline & P1.1 & No effect of treatment/therapy failure & There is neither improvement nor worsening of the patient's symptoms \\
\hline & $\mathrm{P} 1.2$ & Sub-optimal drug effect & There is improvement in the patient's symptoms, but not to the intended target \\
\hline & $\mathrm{P} 1.3$ & Wrong effect of drug treatment & NA \\
\hline & $\mathrm{P} 1.4$ & Untreated indication & There is a symptom (or an anticipated symptom) requiring drug therapy that is not treated \\
\hline \multirow{4}{*}{$\begin{array}{l}\text { Adverse drug } \\
\text { events }\end{array}$} & $\mathrm{P} 2$ & & Patient suffers, or will suffer, from an adverse drug event \\
\hline & $\mathrm{P} 2.1$ & Non-allergic adverse reaction & $\begin{array}{l}\text { An unintended pharmacological effect from an adverse drug event not suspected as an } \\
\text { allergic reaction (or toxic effect) commonly known to be related to the prescribed drug at } \\
\text { doses normally used for the intended indication (e.g. side effects, intolerable intended } \\
\text { pharmacological effect, e.g. hypotension from the use of antihypertensive agent) }\end{array}$ \\
\hline & $\mathrm{P} 2.2$ & Allergic drug reaction & $\begin{array}{l}\text { An unintended pharmacological effect from an adverse drug event suspected as an allergy } \\
\text { reaction or toxicity, commonly known to be related to the prescribed drug at doses } \\
\text { normally used for the intended indication (e.g. rash and penicillin) }\end{array}$ \\
\hline & $\mathrm{P} 2.3$ & Toxic adverse reaction & $\begin{array}{l}\text { An unintended pharmacological effect related to the drug at doses higher than maximum } \\
\text { dose normally used for the intended indication or adverse effect cause by accumulated } \\
\text { doses }\end{array}$ \\
\hline \multirow[t]{3}{*}{ Treatment costs } & P3 & & The drug treatment is more expensive than necessary \\
\hline & P3.1 & Drug treatment more costly than necessary & There is an alternative drug that is cheaper, but is not being used \\
\hline & P3.2 & Unnecessary drug treatment & The drug that is newly (or previously) prescribed is not required (or no longer required) \\
\hline \multirow[t]{4}{*}{ Other } & $\mathrm{P} 4$ & & Other causes not specified above \\
\hline & P4.1 & $\begin{array}{l}\text { Patient dissatisfied with therapy despite optimal } \\
\text { clinical and economic treatment outcomes }\end{array}$ & Self-explanatory \\
\hline & P4.2 & Drug administration problems & $\begin{array}{l}\text { Difficulties in administering the appropriate drug at the correct doses to the intended patient } \\
\text { (e.g. paracetamol suppository ( } 540 \mathrm{mg} \text { ) was prescribed, but the preparation available at } \\
\text { the dispensary is a } 240 \text {-mg suppository; incomplete instructions of drug administration; } \\
\text { any circumstance that hinders drug administration) }\end{array}$ \\
\hline & P4.3 & Delay in treatment & Self-explanatory \\
\hline \multirow[t]{11}{*}{ Drug selection } & $\mathrm{C} 1$ & & The cause of the DRP is related to the selection of the drug \\
\hline & $\mathrm{C} 1.1$ & Inappropriate drug (including contra-indication) & The wrong drug is selected or the selected drug is contraindicated for the patient. \\
\hline & & & $\begin{array}{l}\text { Wrong drug is, for example, a patient who is supposed to be on antibiotic A, but is } \\
\text { administered antibiotic B }\end{array}$ \\
\hline & & & $\begin{array}{l}\text { Contraindicated drug use is, for example, a patient who received a drug to which he had } \\
\text { previously experienced an allergy reaction }\end{array}$ \\
\hline & $\mathrm{C} 1.2$ & Inappropriate combination of drugs & $\begin{array}{l}\text { The selected drug interacts (or has the potential to interact) with another } \operatorname{drug}(\mathrm{s}) \text {, food or } \\
\text { device }\end{array}$ \\
\hline & $\mathrm{C} 1.3$ & $\begin{array}{l}\text { Inappropriate duplication of therapeutic group or } \\
\text { active ingredient }\end{array}$ & More than one drug of the same therapeutic group or active ingredient is used concurrently \\
\hline & $\mathrm{C} 1.4$ & Indication for drug treatment not noticed & $\begin{array}{l}\text { The drug that is indicated to treat a symptom is not used because the existence of the } \\
\text { symptom is not noticed }\end{array}$ \\
\hline & $\mathrm{C} 1.5$ & Too many drugs prescribed for an indication & More than the necessary drugs are used for treating the same symptom(s) \\
\hline & $\mathrm{C} 1.6$ & More cost-effective drug available & An alternative drug that is cheaper and as effective (or more effective) is not used \\
\hline & $\mathrm{C} 1.7$ & $\begin{array}{l}\text { Synergistic/preventive drug required and not } \\
\text { given }\end{array}$ & $\begin{array}{l}\text { A drug that is required to enhance the existing treatment (synergistic effect) or to prevent the } \\
\text { development of another symptom is not used }\end{array}$ \\
\hline & $\mathrm{C} 1.8$ & New indication for drug treatment presented & $\begin{array}{l}\text { The drug has a new indication that requires a change of dosing regimen (e.g. steroid } \\
\text { maintenance dose in post-transplantation and pulse doses in acute rejection) }\end{array}$ \\
\hline \multirow[t]{2}{*}{ Drug form } & $\mathrm{C} 2$ & & Inappropriate drug form \\
\hline & $\mathrm{C} 2.1$ & Inappropriate drug form & Inappropriate drug form and/or formulation \\
\hline Dose selection & $\mathrm{C} 3$ & & The cause of the DRP is related to the selection of the dosage schedule \\
\hline
\end{tabular}


Table 5 (continued)

\begin{tabular}{|c|c|c|c|}
\hline $\begin{array}{l}\text { Main category: } \\
\text { types of MRPs }\end{array}$ & Codes & Sub-categories & Operational definition \\
\hline & $\mathrm{C} 3.1$ & Drug dose too low & Dose is insufficient to achieve the therapeutic outcome \\
\hline & $\mathrm{C} 3.2$ & Drug dose too high & Dose is more than necessary to achieve the therapeutic outcome \\
\hline & $\mathrm{C} 3.3$ & Dosage regimen not frequent enough & Dosing frequency is insufficient to achieve the therapeutic outcome \\
\hline & $\mathrm{C} 3.4$ & Dosage regimen too frequent & Dosing frequency is more than necessary to achieve the therapeutic outcome \\
\hline & $\mathrm{C} 3.5$ & No therapeutic drug monitoring & Serum level for a drug with a narrow therapeutic index, not monitored \\
\hline & $\mathrm{C} 3.6$ & $\begin{array}{l}\text { Pharmacokinetic problem requiring dose } \\
\text { adjustment }\end{array}$ & Changes in renal function requiring dose adjustment \\
\hline & $\mathrm{C} 3.7$ & $\begin{array}{l}\text { Deterioration/Improvement of disease state } \\
\text { requiring dose adjustment }\end{array}$ & Changes to disease state requiring dose adjustment \\
\hline & $\mathrm{C} 3.8$ & Dose difficult to measure & Prescribed dose difficult to measure \\
\hline \multirow{3}{*}{$\begin{array}{l}\text { Treatment } \\
\text { duration }\end{array}$} & $\mathrm{C} 4$ & & The cause of the DRP is related to the duration of therapy \\
\hline & $\mathrm{C} 4.1$ & Treatment duration too short & Treatment duration is shorter than necessary \\
\hline & $\mathrm{C} 4.2$ & Treatment duration too long & Treatment duration is longer than necessary \\
\hline \multirow[t]{12}{*}{$\begin{array}{l}\text { Medication } \\
\text { errors }\end{array}$} & $\mathrm{C} 5$ & & $\begin{array}{l}\text { Mishaps or accidents during at any stage of drug handling, prescribing, transcribing, } \\
\text { dispensing and administering }\end{array}$ \\
\hline & C5.1 & $\begin{array}{l}\text { Inappropriate timing of administration and/or } \\
\text { dosing intervals }\end{array}$ & Error in the process of drug administration \\
\hline & C5.2 & Drug underused/under-administered & Error in the process of drug administration \\
\hline & C5.3 & Drug overused/over-administered & Error in the process of drug administration \\
\hline & C5.4 & Drug not taken/administered at all & Error in the process of drug administration \\
\hline & $\mathrm{C} 5.5$ & Wrong drug taken/administered & Error in the process of drug administration \\
\hline & C5.6 & Drug abused (unregulated overuse) & Self-explanatory \\
\hline & $\mathrm{C} 5.7$ & Patient unable to use drug/drug form as directed & Moved to category patient factor (C7.5) \\
\hline & $\mathrm{C} 5.8 \mathrm{a}$ & Prescribing error in decision making & Error in deciding treatment \\
\hline & $\mathrm{C} 5.8 \mathrm{~b}$ & Prescribing error in prescription writing & Error in writing prescription \\
\hline & C5.9 & Dispensing error & Error in dispensing the prescribed drug \\
\hline & $\mathrm{C} 5.10$ & Dilution error & Error in the process of diluting a drug to its prescribed concentration \\
\hline \multirow[t]{2}{*}{ Drug supply } & C6.1 & Prescribed drug not available & Prescribed drug not available for use \\
\hline & C6.2 & $\begin{array}{l}\text { Difficulty in obtaining repeat prescription from } \\
\text { the community }\end{array}$ & $\begin{array}{l}\text { There is a problem in obtaining repeat prescription(s) from the general practitioner (GP) or } \\
\text { the community pharmacy }\end{array}$ \\
\hline \multirow[t]{9}{*}{ Patient factor } & $\mathrm{C} 7$ & & The cause of the DRP can be related to the personality or behaviour of the patient \\
\hline & C7.1 & Patient forgot to use/take drug & Self-explanatory \\
\hline & $\mathrm{C} 7.2$ & Patient used unnecessary drug & Self-explanatory \\
\hline & $\mathrm{C} 7.3$ & $\begin{array}{l}\text { Patient took food that interacts with the } \\
\text { prescribed drug(s) }\end{array}$ & Self-explanatory \\
\hline & C7.4 & Patient stored drug inappropriately & Self-explanatory \\
\hline & C7.5 & Patient refused to take the drug & Self-explanatory \\
\hline & C7.6 & Patient unable to use the drug & Self-explanatory \\
\hline & $\mathrm{C} 7.7$ & $\begin{array}{l}\text { Patient (parent/carer) forgot to obtain repeat } \\
\text { prescription(s) from the community }\end{array}$ & Self-explanatory \\
\hline & $\mathrm{C} 7.8$ & $\begin{array}{l}\text { Poor understanding of treatment plan and } \\
\text { medications }\end{array}$ & Self-explanatory \\
\hline \multirow[t]{8}{*}{ Others } & $\mathrm{C} 8$ & & Other causes not specified above \\
\hline & C8.1 & Poor medication reconciliation & Discrepancies between the patient's own drugs with those prescribed on admission. \\
\hline & & & Discrepancies between drugs planned to take home and the ones on discharge prescriptions \\
\hline & $\mathrm{C} 8.2$ & Unwanted side effects & Known undesirable effect of a drug other than the intended therapeutic effects \\
\hline & $\mathrm{C} 8.3$ & Inappropriate drug administration site/route & Wrong site and/or route for the prescribed drug \\
\hline & $\mathrm{C} 8.4$ & Dependent on enteral feed tubes & The patient is dependent on enteral feeding tubes for the administration of medicines \\
\hline & C8.5 & $\begin{array}{l}\text { Difficulty in obtaining information from the } \\
\text { general practitioner }\end{array}$ & Self-explanatory \\
\hline & C8.6 & New dose not altered by the general practitioner & Self-explanatory \\
\hline
\end{tabular}

$N A$ not applicable 


\section{Appendix 2}

Table 6 Contributory factors for medication-related problems (MRPs) at the inpatient and outpatient renal clinic*

\begin{tabular}{|c|c|c|c|c|}
\hline \multirow[b]{2}{*}{ Contributory factors for MRPs } & \multicolumn{2}{|c|}{ Inpatient $\left(N_{1}=399\right)$} & \multicolumn{2}{|c|}{ Outpatient $\left(N_{2}=73\right)$} \\
\hline & $n(\%)$ & & $n(\%)$ & \\
\hline C1 Drug selection & 72 & $(18.0)$ & 3 & $(4.1)$ \\
\hline C1.7 Synergistic/preventive drug not prescribed & 20 & $(5.0)$ & 1 & $(1.4)$ \\
\hline C1.9 No indication & 13 & (3.3) & - & - \\
\hline C1.1 Inappropriate drug & 10 & $(2.5)$ & 1 & (1.4) \\
\hline C1.3 Inappropriate drug duplication & 9 & $(2.3)$ & 1 & $(1.4)$ \\
\hline C1.4 Indication for drug not noticed & 7 & $(1.8)$ & - & - \\
\hline C1.5 Too many drugs unnecessarily for the same indication & 6 & $(1.5)$ & - & - \\
\hline C1.2 Inappropriate drug combination & 5 & $(1.3)$ & - & - \\
\hline C1.6 More cost-effective alternative available & 1 & $(0.3)$ & - & - \\
\hline C1.8 New indication & 1 & $(0.3)$ & - & - \\
\hline C2 Inappropriate drug form & 7 & $(1.8)$ & - & - \\
\hline C3 Drug dosage & 97 & $(24.3)$ & 4 & $(5.5)$ \\
\hline C3.2 Dose too high & 23 & $(5.8)$ & 1 & $(1.4)$ \\
\hline C3.1 Dose too low & 17 & $(4.3)$ & 2 & $(2.7)$ \\
\hline C3.4 Dosage regimen too frequent & 15 & $(3.8)$ & - & - \\
\hline C3.7 Deterioration/improvement of disease state & 10 & $(2.5)$ & - & - \\
\hline C3.3 Dosage regimen not frequent enough & 8 & $(2.0)$ & - & - \\
\hline C3.6 Pharmacokinetic problem requiring dosage adjustment & 8 & $(2.0)$ & - & - \\
\hline C3.5 No therapeutic monitoring & 3 & $(0.8)$ & - & - \\
\hline C3.8 Dose difficult to measure & 13 & (3.3) & - & - \\
\hline C4 Treatment duration & 15 & $(3.8)$ & - & - \\
\hline C4.2 Too long & 13 & (3.3) & - & - \\
\hline C4.1 Too short & 2 & $(0.5)$ & - & - \\
\hline C5 Medication errors & 181 & $(45.4)$ & 1 & $(1.4)$ \\
\hline C5.8a Prescribing error in decision making & 104 & $(26.1)$ & 1 & $(1.4)$ \\
\hline C5.8b Prescribing error in prescription writing & 72 & $(18.0)$ & - & - \\
\hline C5.2 Drug over-administered & 2 & $(0.5)$ & - & - \\
\hline C5.1 Inappropriate timing of drug administration/dosing intervals & 2 & $(0.5)$ & - & - \\
\hline C5.9 Dispensing error & 1 & $(0.3)$ & - & - \\
\hline C6 Drug supply & - & - & 8 & $(11.0)$ \\
\hline C6.2 Problems with the process for obtaining repeat prescriptions from the community & - & - & 8 & $(11.0)$ \\
\hline C7 Patient factors & 1 & $(0.3)$ & 31 & $(42.5)$ \\
\hline C7.5 Refused to take medicines & 1 & $(0.3)$ & 6 & $(8.2)$ \\
\hline C7.1 Forgot to take the drug & - & - & 10 & (13.7) \\
\hline C7.7 Forgot to ask for refill prescription from community & - & - & 1 & $(1.4)$ \\
\hline C7.8 Poor understanding of treatment plan and medications & & & 14 & $(19.2)$ \\
\hline C8 Other factors & 26 & $(6.5)$ & 26 & $(35.6)$ \\
\hline C8.2 Unwanted side effects & 14 & (3.5) & 12 & (16.4) \\
\hline C8.1 Poor medication reconciliation & 12 & $(3.0)$ & - & - \\
\hline C8.4 Dependent on NG/PEG for medications & - & - & 8 & $(11.0)$ \\
\hline C8.5 Difficult to obtain information from GP & - & - & 5 & $(6.8)$ \\
\hline C8.6 New dose not altered by the GP & - & - & 1 & (1.4) \\
\hline
\end{tabular}

$N G$ nasogastric, $P E G$ percutaneous endoscopic gastrostomy 
Open Access This article is distributed under the terms of the Creative Commons Attribution License which permits any use, distribution, and reproduction in any medium, provided the original author(s) and the source are credited.

\section{References}

1. Hepler CD, Strand LM (1990) Opportunities and responsibilities in pharmaceutical care. Am J Hosp Pharm 47:533-543

2. Hogg RJ, Furth S, Lemley KV, Portman R, Schwartz GJ, Coresh J, Balk E, Lau J, Levin A, Kausz AT, Eknoyan G, Levey AS (2003) National Kidney Foundation's Kidney Disease Outcomes Quality Initiative clinical practice guidelines for chronic kidney disease in children and adolescents: evaluation, classification, and stratification. Pediatrics 111:1416-1421

3. Rashed AN, Neubert A, Tomlin S, Jackman J, Alhamdan H, AlShaikh A, Attar A, Aseeri M, Wilton L, Wong I (2012) Epidemiology and potential associated risk factors of drug-related problems in hospitalised children in the United Kingdom and Saudi Arabia. Eur J Clin Pharmacol 68(12):1657-1666

4. Rashed AN, Neubert A, Tomlin S, Jackman J, Alhamdan H, AlShaikh A, Attar A, Aseeri M, Wilton L, Wong I (2013) Drugrelated problems found in children attending an emergency department in Saudi Arabia and in the United Kingdom. Int J Clin Pharm 35(3):327-331

5. Ibrahim N, Wong IC, Patey S, Tomlin S, Sinha MD, Jani Y (2013) Drug-related problem in children with chronic kidney disease. Pediatr Nephrol 28:25-31

6. Pruthi R, O'Brien C, Braddon F, Lewis M, Maxwell H, Stojanovic J, Tse Y, Inward C (2012) Chapter 7: demography of the UK paediatric renal replacement therapy population in 2012. UK Renal Registry 16th Annual Report 2012. Available at: http://www.renalreg.com/ Report-Area/Report\%202013/07-Chap-07.pdf. Accessed 28 January 2014

7. Jani YH, Barber N, Wong IC (2010) Paediatric dosing errors before and after electronic prescribing. Qual Saf Health Care 19(4):337-340

8. Ghaleb MA, Barber N, Franklin BD, Wong IC (2010) The incidence and nature of prescribing and medication administration errors in paediatric inpatients. Arch Dis Child 95(2):113-118

9. Rashed AN, Wilton L, Lo CCH, Kwong BYS, Leung S, Wong ICK (2014) Epidemiology and potential risk factors of drug-related problems in Hong Kong Paediatric wards. Br J Clin Pharmacol 77(5):873-879

10. Dean BS, Barber ND (1999) A validated, reliable method of scoring the severity of medication errors. Am J Health Syst Pharm 56(1):57-62

11. Pharmaceutical Care Network Europe Foundation (PCNE) DRP Classification Scheme version 6.2. Available at: http://www.pcne. org/sig/drp/documents/PCNE\%20classification\%20V6-2.pdf. Accessed 1 March 2011

12. Kaplan B, Mason NA, Shimp LA, Ascione FJ (1994) Chronic hemodialysis patients. I. Characterization and drug-related problems. Ann Pharmacother 28(3):316-319

13. Grabe DW, Low CL, Bailie GR, Eisele G (1997) Evaluation of drugrelated problems in an outpatient hemodialysis unit and the impact of a clinical pharmacist. Clin Nephrol 47(2):117-121

14. Manley HJ, Drayer DK, Muther RS (2003) Medication-related problem type and appearance rate in ambulatory hemodialysis patients. BMC Nephrol 4:1-7

15. Cardone KE, Bacchus S, Assinom MM, Pai AB, Manley HJ (2010) Medication-related problems in CKD. Adv Chronic Kidney Dis 17(5):404-412
16. Salgado TM, Moles R, Benrimoj SI, Fernandez-Llimos F (2012) Pharmacists' interventions in the management of patients with chronic kidney disease: a systematic review. Nephrol Dial Transplant 27(1):276-292

17. Brown C, Hofer T, Johal A, Thomson R, Nicholl R, Franklin BD, Lilford RL (2008) An epistemology of patient safety research: a framework for study design and interpretation. III. End points and measurement. Qual Saf Health Care 7(3):170-177

18. Wong IC, Ghaleb MA, Franklin BD, Barber N (2004) Incidence and nature of dosing errors in paediatric medications: a systematic review. Drug Saf 27(9):661-670

19. Ghaleb MA, Barber N, Frankin BD, Yeung VW, Khaki ZF, Wong IC (2006) Systematic review of medication errors in pediatric patients. Ann Pharmacother 40(10): 1766-1776

20. Wong IC, Basra N, Yeung VW, Cope J (2006) Supply problems of unlicensed and off-label medicines after discharge. Arch Dis Child 91(8):686-688

21. Kaushal R, Bates DW, Landrigan C, McKenna KJ, Clapp MD, Fedrico F, Goldmann DA (2001) Medication errors and adverse drug events in pediatric inpatients. JAMA 285(16):2114-2120

22. Kunac DL, Reith DM (2008) Preventable medication-related events in hospitalised children in New Zealand. N Z Med J 121(1272):1732

23. Belaiche S, Romanet T, Allenet B, Calop J, Zaoul P (2012) Identification of drug-related problems in ambulatory chronic kidney disease patients: a 6-month prospective study. J Nephrol 25(5):782788

24. Castelino RL, Sathvik BS, Parthasarathi G, Gurudev KC, Shetty MS, Narahari MG (2011) Prevalence of medication-related problems among patients with renal compromise in an Indian hospital. J Clin Pharm Ther 36(4):481-487

25. Impicciatore P, Choonara I, Clarkson A, Provasi D, Pandolfini C, Bonati M (2001) Incidence of adverse drug reactions in paediatric in/ out-patients: a systematic review and meta-analysis of prospective studies. Br J Clin Pharmacol 52(1):77-83

26. Brandt JR, Wong CS, Hanrahan JD, Qualls C, McAfee N, Watkins SL (2006) Estimating absolute glomerular filtration rate in children. Pediatr Nephrol 21(12):1865-1872

27. Pai AB, Cardone KE, Manley HJ, St Peter WL, Shaffer R, Somers M, Mehrotra R (2013) Medication reconciliation and therapy management in dialysis-dependent patients: need for a systematic approach. Clin J Am Soc Nephrol 18(11):1988-1999

28. St Peter WL, Wazny LD, Patel UD (2013) New models of chronic kidney disease care including pharmacists: improving medication reconciliation and medication management. Curr Opin Nephrol Hypertens 22(6):656-662

29. Huynh C, Jani Y, Wong IC, Dewchand B, Tomlin S (2013) What is the current practice of medicines reconciliation in children nationally in the UK? Int J Pharm Pract 21(1):62-65

30. Conroy S, Carroll WD (2009) Prescribing in paediatrics. Arch Dis Child Educ Pract Ed 94(2):55-59

31. Dean AJ, Walters J, Hall A (2010) A systematic review of interventions to enhance medication adherence in children and adolescents with chronic illness. Arch Dis Child 95(5):717-723

32. Wong IC, Wong LY, Cranswick NE (2009) Minimising medication errors in children. Arch Dis Child 94(2):161-164

33. So TY, Layton JB, Bozik K, Farrington E, Gipson PE, Gibson K, Primack W, Conley W, Gipson DS, Ferris M (2011) Cognitive pharmacy services at a pediatric nephrology and hypertension clinic. Ren Fail 33(1):19-25

34. Stemer G, Lemmens-Gruber R (2011) Clinical pharmacy activities in chronic kidney disease and end-stage renal disease patients: a systematic literature review. BMC Nephrol 12:35. doi:10.1186/14712369-12-35 